the result of similar biochemical lesions ? Though a rise in serum enzyme levels may in some instances help to define cases and carriers, here one is observing merely an end result. Incidentally, no reference to serum creatine kinase appears in the index though the value of this enzyme in diagnosis is discussed.

The inclusion of entities as dissimilar as, for example, the Duchenne type of dystrophy and myotonic dystrophy within the same general category of inherited disease is merely a taxonomic convenience, since the only common factor appears to be the involvement of muscle and this in distinctly different ways. Again, the associated features of these two diseases taken as representatives of the group are revealing. In myotonic dystrophy, testicular atrophy, frontal baldness, and cataract are well known, but the mental retardation in some boys with Duchenne dystrophy is less well known. As the authors indicate, the biochemical lesions responsible for these varied non-muscular manifestations of the dystrophies are likely to be as heterogeneous as are the clinical features and the modes of inheritance. One feels that major advances in our understanding of the dystrophies are imminent. They are certainly needed.

This volume of Progress in Medical Genetics provides a further addition to a useful series of authoritative reviews.

R. HARRIS

Annual Review of Genetics, Volume 1, 1967. Edited by H. L. Roman. Associate Editors Laurence M. Sandler and Gunther S. Stent. (Pp. vii +334 ; illustrated. $\$ 8.50$ in U.S.A., $\$ 9.00$ elsewhere.) Palo Alto, California: Annual Reviews Inc. 1967.

This is the first volume of a projected series of 'Annual Reviews of Genetics', from the same publishers as the similar 'Annual Reviews' which cover a variety of scientific disciplines from nuclear science to psychology. The editorial committee point out that, though reviews of various genetical subjects are not lacking, they are 'scattered in a variety of periodicals'; the stated object of the present volume is to bring together 'critical rather than comprehensive reviews' on topics of interest.

The book consists of 13 separate articles, of about 2030 pages each, covering a wide range of such topics as 'Human Genetics' (H. Eldon Sutton); 'Population Genetics' (R. C. Lewontin); 'Biochemical Aspects of Drosophila' (H. K. Mitchell); 'Structural Relationships between Gene and Protein' (Charles Yanofsky), etc. The choice of subject matter included in each review is of course a personal one, the limitation of space necessitating a rigid selection. Different contributors react to the challenge in different ways. Some, as exemplified by the first chapter on human genetics, provide staccato listings and short notes on a large number of recent developments, while others such as Sheldon Wolff's excellent discussion of radiation genetics take a particular controversy and devote most of the available space to a closely reasoned examination of the current evidence on the point in question.

For the most part, the level at which the subject matter is treated is such as to be comprehensible to a nonspecialist with a general genetical knowledge. A helpful point is the noting at the start of each chapter, of the date on which the literature survey was concluded. The production of the book is of a high standard, but the uniform appearance of over 300 pages of text is somewhat monotonous. Skimming rapidly through the chapters would be easier if the italicized subheadings were more prominently displayed, and a greater number of illustrations would be welcome.

There will be few geneticists who will not find something of use and interest in this book, but a small number will read it avidly from cover to cover. Perhaps the greatest value of a volume of this sort is that it provides easy access to areas of genetics with which one is not usually concerned. One result of the recent rapid expansion of genetical knowledge has been a deterioration of intradisciplinary communication; though this may be an inevitable development, anything which will tend to minimize it is surely of value.

Martin Bobrow

\section{Proceedings of the Third International Congress of}

Human Genetics. (The University of Chicago, Chicago, Illinois, U.S.A., September 5-10, 1966.) Edited by James F. Crow and James V. Neel. (Pp. xviii + 578; illustrated + tables. 138s.) Baltimore: The John Hopkins Press. U.K. DistributorsLondon: Oxford University Press. 1968.

This volume contains most of the papers read at plenary sessions and arranged symposia at the Third International Congress of Human Genetics held in Chicago in September 1966. It is inevitably somewhat of a mixed bag of opening statements, speculative papers on the past and future of man, reports of specific research enterprises, and reviews designed to establish the present status of knowledge of certain subjects. Inevitably also it is difficult to justify the printing of some addresses except that it would have been invidious to leave them out.

However, there are some excellent papers, some of the reviews form good sources of references, and there are a few reports of interesting new work. The volume can be recommended as introductory and stimulating reading for those becoming interested in human genetics.

The editing has been done carefully and effectively, and the printing and diagrams are of a high standard.

A. C. Stevenson

\section{Symposium on Autoimmunity and Genetics} Supplement to Clinical and Experimental Immunology, Vol. 2, December, 1967. Edited by W. W. Buchanan and W. J. Irvine. (Pp. 131; illustrated + tables. 30s.) Oxford: Blackwell Scientific Publications. 1967.

The first volume, published as a supplement to Clinical and Experimental Immunology, presents the proceedings of a symposium on auto-immunity and 
genetics held in Glasgow in June 1966. Though much of the data have already been published in a variety of journals, the present work is a useful summary of the present situation in this important field. With the exception of one chapter on auto-immune disease in inbred mice, the volume is devoted to the study of clinical problems. The subjects include family studies in patients with thyroiditis, rheumatoid arthritis, irondeficiency anaemia, lupus erythematous and other connective tissue disorders, and the incidence of autoantibodies in twins. There is a particularly pertinent chapter on the pitfalls of genetic studies as illustrated by a review of the 17 studies conducted on patients with rheumatoid arthritis in whom familial aggregation has been reported. Deficiencies in the criteria for selection of the patients are analysed and the too ready acceptance that familial aggregation of cases necessarily implies a genetic basis of the disorder is critically discussed. Clinicians of many disciplines will find this volume of value.

J. H. THOMSON

Phenotypic Expression. Immunological, Biochemical, and Morphological. A Symposium Organized by Milton N. Goldstein, San Francisco, May 31-June 3, 1966. In Vitro, Vol. 2. Tissue Culture Association, Inc. (Pp. xi +170 ; illustrated + tables. 87s. 6d.) Baltimore, Williams \& Wilkins; Edinburgh: E. \& S. Livingstone. 1968.

'In vitro' is the vehicle by which the American Tissue Culture Association publishes invited papers at its annual symposium and also the abstracts of proferred papers. This volume, which records the 1966 meeting, is of particular genetical interest in that the papers were designed to examine various types of phenotypic expression of genes studied at the molecular and structural level. It also contains the Association's report on their proposed terms for use in relation to animal tissue culture; these include their definitions of cell strain; clone; diploid cell line; euploid, mixoploidy; endopolyploidy; and toxicity. The last definition is particularly unusual since it can include change of the rate of growth of cells.

Many of the proffered papers are of a high standard. It would have been helpful if these abstracts carried references to work quoted.

The invited papers are exceptionally good. Hirschhorn gives fascinating evidence that small lymphocytes produce various antibodies, and he relates this ability to the function of their lysosomes. Hiramoto and Hamlin give detailed investigations of the possibility that any one cell may produce two different antibodies, and they discuss the genetical problems involved in such a possibility. Ephrussi's communication deals with somatic hybrids between hamster and either rat or mouse cells, and proves the hybridization by karyological analysis and by the analysis of the LDH proteins they produce.

Ohno gives both karyological and genetic evidence for somatic segregation in many animals; apparently only certain chromosomes are involved in such segregations. In mammals, it is particularly the splenic cells that show this phenomenon, and he speculates on how this may affect immunologically competent cells. Black reports $\mathbb{D}$ that DNA, isolated from oncogenic virus, can induce the $\overparen{\mathbb{Q}}$ host cell to produce the specific antigen which is found when the cells undergo a malignant transformation. It $\overrightarrow{\bar{N}}$ is left open whether this is due to the integration of the $\overrightarrow{0}$ viral DNA into the genome of the host cell, or whether it $\frac{5}{5}$ is due to specific derepression of the host cell's genome, $\frac{\bar{D}}{\bar{D}}$ as Green suggests in his article. Franks points out the $\frac{\overrightarrow{ }}{\overrightarrow{ }}$ need to study the antigens present on cultured cells be- $\propto$ cause of their importance for genetic studies on somatic in cells; but apparently almost all cell lines contain some $\vec{D}$ cells that are antigen-negative as well as those that are antigen-positive. While Franks discusses the role of $\overrightarrow{\vec{\omega}}$ aneuploidy in this apparent anomaly, Merchant and coworkers show that cells can lose their surface antigens when grown in culture.

Krooth's communication describes two selective sys- ir tems for culturing human diploid cells, which allow the detection of genetic change at some Mendelian loci. He gives evidence for the existence of two types of acatalasia and in glucose-6-phosphate dehydrogenase deficiency, which can be detected in diploid cell strains grown in culture. His results on galactosaemia and on orotic aciduria are given in some detail. De Mars and Leroy show the value of phase-contrast microscopy for screening tissue cultures, and describe abnormal cells in a case of Hurler's disease; they suggest that the HurlerHunter disease could be a genetic defect of the lysosomes. Though their histochemical evidence leaves much to be desired, their culture methods are of interest.

Joseph Chayes

Primates in Medicine. A Series in Experimental Medicine and Surgery in Primates, Vol. 1. First Holloman Symposium on Primate Immunology and Molecular Genetics. Edited by C. H. Kratochvil. (Pp. $x v+99 ; 33$ figures +28 tables. S. Fr./DM. $16.50 ; \$ 4.00$; 30s.) Basel, S. Karger. New York. 1968 .

This is a report of a symposium, held in the United States in 1966, on the immunology and molecular genetics of primates. The studies reported deal with such topics as the blood groups and the pattern of immunoglobins in chimpanzees and other non-human primates. Though the data are of interest as a contribution to comparative biochemistry and immunology, this work has not yet developed to the stage where the direct relevance to the human situation is apparent, and is therefore of limited medical interest.

J. H. Thомson

Cell Differentiation. A CIBA Foundation Symposium. Edited by A. V. S. de Reuck and Julie Knight. (Pp. 257; illustrated + tables.) London: J. \& A. Churchill. 1967.

This volume is a record of one of the small international symposia organized by the Ciba Foundation in London. Perhaps the clearest summing up of this

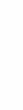

